\title{
EFFECT OF FINISH LINE LEVEL OF ALL CERAMIC CROWN ON STRESS DISTRIBUTION WITHIN DENTIN OF MAXILLARY CENTRAL INCISOR WITH AN ABFRACTION LESION
}

\author{
Adel A. El-Badawy* ${ }^{*}$ and Mohammed H. Abdel-Aziz*
}

\begin{abstract}
Purpose: to evaluate by means of three dimensional finite element analysis, the effect of finish line location on stress distribution on dentin of maxillary central incisor affected by abfraction lesion and covered with IPS e. max (Lithium di silicate) crown.
\end{abstract}

Statement of the problem: In some cases of abfraction, the tooth need to be covered with full coverage crown, but, location of finish line may affect dentin integrity.

Materials and Methods: 3D finite element model of unprepared maxillary central incisor was made. By deleting method, IPS e.max crown w as designed and geometric dimensions of prepared tooth were introduced as the following guidelines, $2 \mathrm{~mm}$ incisal reduction, $1.5 \mathrm{~mm}$ reduction of labial surface and $1 \mathrm{~mm}$ circumferential shoulder finish line. The position of labial finish line was designed in three different levels apical to the upper margin of the abfraction lesion (0.5. 1.0 and $1.5 \mathrm{~mm}$ ) forming three models to be tested (A, B and C) respectively in addition to unprepared control model.

Results: For all tested four models, the calculated stresses with $125^{\circ}$ applied load were higher than that with $60^{\circ}$ with statistical significant differences. The calculated stresses at the control model in both directions of applied load were lower than that in other tested models (A, B and C) with statistical significant differences. For control model at $125^{\circ}$ applied load, Von Mises equivalent stress value was (40.27 MPa), whereas, in case of $60^{\circ}$ applied load, was (26.33 MPa). For model (A) where the finish line of IPS e.max crown is established $0.5 \mathrm{~mm}$ apical to the upper edge of the abfraction lesion, Von Mises equivalent stress values were (22.14 \& $39.68 \mathrm{MPa})$ respectively.

Conclusion: In all tested models, maximum stresses increased with increasing the angle of applied load, and model (B and C) provided more favorable stress distribution than that in model (A).

* Assistant professor of Crown and Bridge, Faculty of Dental Medicine, Al-Azhar University. 


\section{INTRODUCTION}

Abfraction is a popular non carious lesion which has been defined as loss of tooth structures in the cervical region (usually on the labial side), resulted from the effect of continuous occlusal stress, ends by loss of bonds between hydroxyapatite crystals of both dentin and enamel, followed by formation of wedge shaped defect, sharp in its internal and external edges. ${ }^{(1-3)}$

Occurrence of abfraction increases with patient's age, which accompanied with prolonged fatigue of tooth structures through a long period of time. ${ }^{(4-5)}$ Restoration of abfraction is necessary to reduce hypersensitivity, to prevent further tooth structure loss, and for esthetic demands. Resin composites have been suggested to restore this defect, owing to their esthetic properties and to ease of handling characteristics. ${ }^{(6-7)}$ However, failure of hybrid layer formation can be observed, where, marginal gap of the restoration may occur as a result of persistence of occlusal load with a possibility of appearing a new lesion apical to the first one. ${ }^{(8-9)}$

In case of abfraction lesion, the tooth need to be covered with full coverage restoration, taking in consideration that, the site of finish line of the prepared tooth may affect the integrity of the tooth structures, as well as, used restoration. ${ }^{(10)}$ Finite element analysis is more conservative method for stress analysis where, stress distribution and its value can be analyzed for any part of the simulated model and the analysis can be repeated without altering in material properties. ${ }^{(11-12)}$ The purpose of this study was to evaluate by means of three dimensional finite element analysis, the effect of finish line location on stress distribution on dentin of maxillary central incisor affected by abfraction lesion and covered with IPS e. max (Lithium di silicate) crown

\section{MATERIALS AND METHODS}

Maxillary right central incisor with $26 \mathrm{~mm}$ length (free of dental caries, restorations and incisal attrition) was selected and fixed at a glass slab (2 X $2 \mathrm{~cm}$ ) with a piece of wax. Using dental surveyor, the tooth was aligned with their axis perpendicular to the horizontal plane of the mold, then, a plastic mold ( 2 X 2 X $3 \mathrm{~cm}$ ) was assembled over the glass slab. Computerized tomography (CT) image was performed (CS 9300, Carestream, AGXL012) with image quality $(120 \mathrm{kV}, 150 \mathrm{~mA})$ and slice volume of $0.5 \mathrm{~mm}$ thickness to divide the tooth into 52 sections. Scanning was performed in a labio palatal direction starting from the incisal edge up to apical foramen to obtain 53 image levels $(0,1,2$, $3,4 \ldots \ldots .52 \mathrm{~mm})$. From Computerized tomography scan, $1240 \mathrm{~K}$ points were obtained, each $\mathrm{K}$ point has a three distances, $\mathrm{x}, \mathrm{y}$ and $\mathrm{z} .\{\mathrm{x}$ : is the distance from " $\mathrm{X}$ " axis, $\mathrm{y}$ : is the distance from "Y" axis, while $\mathrm{z}$, is the slice level $(0.5 \mathrm{~mm}$ increase with each level) $\}$. The collected $\mathrm{x}, \mathrm{y}$, and $\mathrm{z}$ distances were introduced into 3D CAD software (PRO/E) for stress analysis (ANSYS 5.4 finite element software) to obtain finite element model. Then, the model divided into cubical volumes. The volumes were digitally refined and automatically mashed with eight nodes brick for each with three degrees of freedom per nodes forming the original model for unprepared tooth with its internal morphology including (131294) elements and (202464) nodes.

From the spongy bone volume, $0.25-\mathrm{mm}$ were deleted representing periodontal ligament, $0.25-\mathrm{mm}$ for lamina dura, and $1.5 \mathrm{~mm}$ cortical bone were developed. The residual area of bone was considered as cancellous type ${ }^{(13-14)}$ and a cylindrical bone section of $20 \mathrm{~mm}$ height and $10 \mathrm{~mm}$ diameter was modeled. The abfraction lesion is represented in the model as a wedge shaped defect, its lower margin at the level of cervical line of which dimensions are $2 \mathrm{~mm}$ vertically and horizontally, also with $2 \mathrm{~mm}$ depth. ${ }^{(10)}$ (The model at this stage representing an unprepared tooth which used as a control model). Geometric dimensions of prepared tooth were introduced as the following guidelines, $2 \mathrm{~mm}$ incisal 
reduction, $1.5 \mathrm{~mm}$ reduction of labial surface and $1 \mathrm{~mm}$ circumferential shoulder finish line. ${ }^{(15)}$ The position of labial finish line was designed in three different levels apical to the upper margin of the abfraction lesion $(0.5,1.0$ and $1.5 \mathrm{~mm})$ forming three models to be tested (A, B and C) respectively in addition to the un prepared control model. The basic geometric configurations of IPS e-max crown and its dimensions in millimeters in addition to $100 \mu$ thickness of resin cement layer were introduced into the ANSYS software program. Young's Modulus, and Poisson's ratio of the tooth components as well as the used materials" as seen in table 1", were introduced to the ANSYS software program which in turn calculated stresses under a load of 100 Neotn applied at $60^{\circ}$ (tearing) and $125^{\circ}$ (protrusion) ${ }^{(16)}$ to identify maximum Von Mises equivalent stresses according to the following formula. Where S1, S2 and $\mathrm{S} 3$ are known as the principle stresses.

$$
\left\{V m=1 / \sqrt{ } 2 \times \sqrt{ }(S 1-S 2)^{2}+(S 2-S 3)^{2}=(S 3-S 2)^{2}\right\}
$$

Finally, percentage of the maximum Von Mises equivalent stress values between each model (VMM) and control model(VMC) were obtained. ${ }^{(20)}$ The data were collected and statistically analyzed by ANOVA one-way test using statistical-package of social science (SPSS) statistic software (SPSS for windows, version 21.0, SPSS Inc. Chicago).

TABLE (1) Mechanical properties of dental structures and used materials

\begin{tabular}{|l|c|c|}
\hline \multicolumn{1}{|c|}{ Material } & $\begin{array}{c}\text { Modulus of } \\
\text { elasticity Mpa }\end{array}$ & Poisson's ratio \\
\hline Enamel $^{(\mathbf{1 7 )}}$ & 84100 & 0.41 \\
\hline Dentin $^{(\mathbf{1 7 )}}$ & 18600 & 0.31 \\
\hline Pulp $^{(\mathbf{1 7})}$ & 2 & 0.45 \\
\hline Periodontal ligament $^{(\mathbf{1 8 )}}$ & 68.9 & 0.45 \\
\hline Cortical bone $^{(\mathbf{1 8})}$ & 13700 & 0.30 \\
\hline Cancellous bone $^{(\mathbf{1 8})}$ & 13700 & 0.30 \\
\hline IPS e. max core $^{(\mathbf{1 8})}$ & 65000 & 0.24 \\
\hline IPS e. max veneer $^{(\mathbf{1 8})}$ & 65000 & 0.24 \\
\hline Resin cement $^{(\mathbf{1 9 )}}$ & 18.3 & 0.33 \\
\hline
\end{tabular}

\section{RESULTS}

Based on the results obtained from finite element analysis, Von Mises equivalent stress value in dentin were listed in table 2 .

TABLE (2) Von Mises equivalent stress value in dentin with two directions of applied load $\left(60^{\circ}\right.$ and $\left.125^{\circ}\right)$

\begin{tabular}{|c|c|c|c|}
\hline \multirow{2}{*}{ Models } & Angle & Von Mises (MPa) & \multirow{2}{*}{ \% VMM / VMC } \\
\hline \multirow{2}{*}{ (A) } & $60^{\circ}$ & 26.33 & \\
\cline { 2 - 3 } & $125^{\circ}$ & 40.27 & 84.08 \\
\cline { 2 - 3 } & $125^{\circ}$ & 32.68 & 81.15 \\
\hline \multirow{2}{*}{ (B) } & $60^{\circ}$ & 10.18 & 38.66 \\
\cline { 2 - 3 } & $125^{\circ}$ & 19.59 & 48.64 \\
\hline \multirow{2}{*}{ (C) } & $60^{\circ}$ & 10.16 & 38.58 \\
\cline { 2 - 3 } & $125^{\circ}$ & 19.56 & 48.56 \\
\hline
\end{tabular}

VMM Von Mises equivalent stress value for each model VMC Von Mises equivalent stress value for control model

The loads that have been applied on IPS e.max crown which were either at $60^{\circ}$ (tearing) and $125^{\circ}$ (protrusion) were analyzed into three stress components (shear, tensile and compressive) and are present as a color strips or figures for the tooth components as well as the used materials" as seen in figure 1". For all tested four models (Control, A, B and C) The calculated stresses with $125^{\circ}$ (protrusion) load were higher than that with $60^{\circ}$ (tearing) load with statistical significant differences (at the level of $\mathrm{P}$ value $<0.05$ ). also, the calculated stresses at the control model in both directions of applied load were lower than that in other tested models (A, B and $C$ ) with statistical significant differences (at the level of $\mathrm{P}$ value < 0.05 ) "as seen in figure 2". For control model where $125^{\circ}$ protrusion load was applied, the stress value was higher at the top of the abfraction wedge shape and then progressively distributed along the defect side walls as well as 


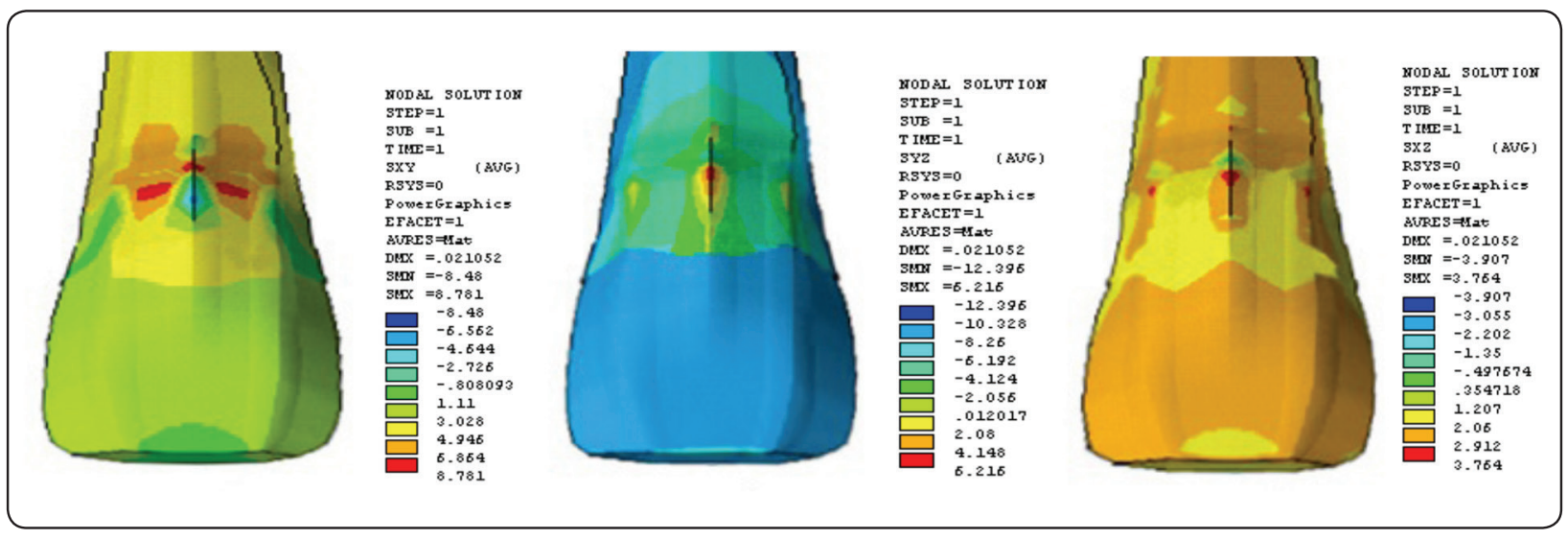

Fig. (1) Finite element models for maxillary central incisor with different directions of applied load $60^{\circ}$ and $125^{\circ}$.

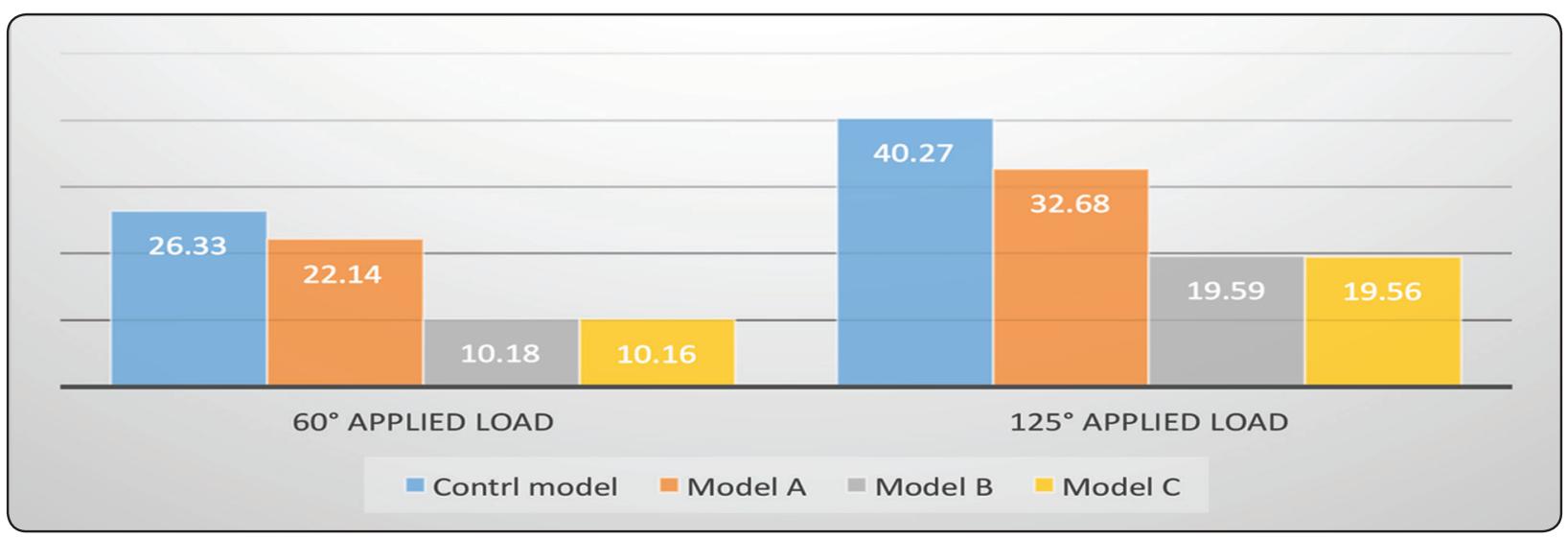

Fig. (2) Bar chart for Von Mises equivalent stress value in dentin with two directions of applied load $\left(60^{\circ}\right.$ and $\left.125^{\circ}\right)$

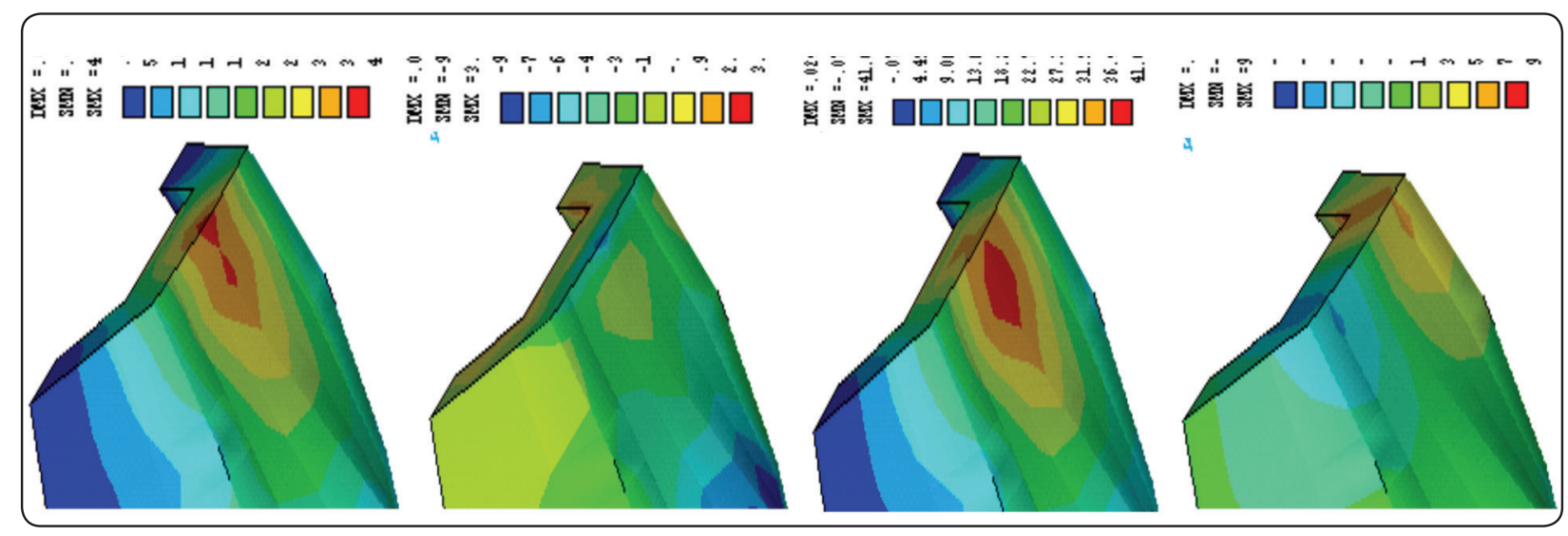

Fig. (3) Finite element models for labial margin of all ceramic crown 
the surrounding cervical area of the labial surface where maximum Von Mises equivalent stress value was (40.27 MPa), whereas, in case of $60^{\circ}$ tearing load, stress distribution on the defect was the same as previously described but, lower in its value where maximum Von Mises equivalent stress value was (26.33 MPa), giving an indication for the effect of eccentric load on the incidence of this lesion. For model (A) where the finish line of IPS e.max crown is established $0.5 \mathrm{~mm}$ apical to the upper edge of the abfraction lesion, stress distribution on the defect was the same as previously described in control model but, lower in its value for both $60^{\circ}$ and $125^{\circ}$ applied loads (84.08 \& $81.15 \%$ ) respectively, where maximum Von Mises equivalent stress values were $(22.14 \& 32.68 \mathrm{MPa})$ respectively. The stress distribution at the buccal part of finish line increased progressively from the lower edge of the abfraction lesion toward the lingual side "as seen in figure 3".

For both (B and C) models where the finish line of IPS e.max crown is set 1.0 and $1.5 \mathrm{~mm}$ above the upper border of the abfraction wedge shaped defect, the stress values on the defect have decreased significantly for both $60^{\circ}$ and $125^{\circ}$ applied loads (38.66 \& $48.64 \%)$ respectively for model (B) and $(38.58 \& 48.56 \%)$ respectively for model (C) where maximum Von Mises equivalent stress values were $(10.18 \& 19.59 \mathrm{MPa})$ and $(10.16 \& 19.56 \mathrm{MPa})$ respectively. The stress distribution at the finish line (buccal) did not spread toward the lingual side giving an indication for good stress distribution "as seen in figure 3". Statistically, there was no significant differences between model (B) and (C) for each direction of applied load.

\section{DISCUSSION}

A structural linear static analysis has been performed to evaluate the stress distribution at the dentin of maxillary central incisor (affected by abfraction lesion) with three levels of buccal finish line for IPS e.max crown in addition to un prepared control model under applied load of $100 \mathrm{~N}$ at $60^{\circ}$ (tearing) and $125^{\circ}$ (protrusion).
In this study, full coverage all ceramic crown has been selected as a treatment modality for abfraction lesion instead of resin composite restorations which may increase plaque accumulation leading to harmful effect to the periodontal health with high caries susceptibility, in addition to difficulty in moisture control with high failure rate for such restoration. ${ }^{(21-22)}$

Lithium disilicate was used as the material of full coverage crown due to several factors, first, it is esthetically accepted with reasonable modulus of elasticity (95 Gpa) in comparison to various restorative dental materials, second, mechanical testing of strength has proven that, the lithium disilicate material demonstrates superior results and finally, the strength of the ceramic material in contact with opposing teeth, to fulfill masticatory functions, is reasonable ${ }^{(23-25)}$.

In this study, computerized tomography was used for construction of maxillary central incisor tooth model which is valid as a research method from different studies ${ }^{(26-27)}$. The finite element results are presented as a color strips representing stresses distributed in the tested model. The stress transforms into three components (tensile, compressive and shear), or gathered together in one equation of stress known as von Mises equivalent stress value which is the most commonly used for calculation and expectation of damage that may happen for the tested matter. ${ }^{(28-29)}$

For all tested models, the result of this study showed that, in case of $60^{\circ}$ applied load the stress distribution is better than that of $125^{\circ}$ applied load. This results are compatible with that of Chander and Padmanabhan ${ }^{(30)}$. On the other hand, the stresses concentrated on the all ceramic crown level and significantly decreased towards the resin cement layer up to the tooth structure in all tested models. This is due to the overall mechanical properties of the IPS e.max which is high in modulus of elasticity (nearly $95 \mathrm{Gpa}$ ) than that of resin cement and tooth structure, this result is in agreement with other. ${ }^{(31-32)}$ 
In case of placement of finish line of IPS emax press crown $0.5 \mathrm{~mm}$ apical to the upper edge of the abfraction lesion (model A), stress level at the top of the abfraction lesion decreased than that at control model. However, the stress was concentrated at the top of the lesion. The stress spread from the finish line of the ceramic crown, passing through the lower edge then through the top of the lesion continuing toward the lingual side. With high possibility of crown fracture. This result was in accordance with that obtained by other study. ${ }^{(15)}$ In case of finish line placement at $1 \mathrm{~mm}$ or $1.5 \mathrm{~mm}$ apical to the upper edge of the lesion (model B and C), the stress was also concentrated at the top of the lesion and its value was lower than that of control model. In addition to that, the stress did not spread from the buccal side toward the lingual side of finish line. Therefore, the possibility of tooth fracture cannot be as high as in the previously mentioned models (control and A). this is may be due to that, the stress is load divided by area, and increased area of the matter leads to better stress distribution with lower effect of tensile stresses, with the action of ferrule effect. ${ }^{(33)}$

\section{CONCLUSION}

Within the limitation of this study, the following conclusions might be drawn:

1. In all tested models, maximum stresses generated by protrusion $\left(125^{\circ}\right.$ applied load) were generally higher than that by tearing $\left(60^{\circ}\right.$ applied load).

2. IPS emax press crown reduced the stress concentration at the top of the lesion, when the finish line was placed below the lower edge of the lesion

3. Model (B and C) provided more favorable stress distribution at the cervical area of the tooth than that in model (A).

4. There were no significant differences in stress distribution between model B and model C.

\section{REFERENCES}

1. Pegoraro LF, Scolaro JM, Conti PC, Telles D, Pegoraro TA. Noncarious cervical lesions in adults, Prevalence and occlusal aspects. J Am Dent Assoc. 2005; 136: 1694-1700.

2. Wood I, Jawad Z, Paisley C, Brunton P. Non-carious cervical tooth surface loss: a literature review. J Dent. 2008; 36(10): 759-766.

3. Chowdhry A, Tandon A, Mehta V, Ramesh G. Abfraction: Concepts Revisited. Int J Oral \& Maxillofacial Pathology. 2013; 3: 58-60.

4. Silva AG, Martins CC, Zina LG, Moreira AN, Paiva SM, Isabela A. Pordeus IA, Magalha CS. The association between occlusal factors and noncarious cervical lesions: A systematic review J Dent. 2013; 41: 9 - 12.

5. Jakupović S, Vuković A, Korać S, Tahmiščija I, Bajsman A. The prevalence, distribution and expression of noncarious cervical lesions (NCCL) in permanent dentition. Mater Sociomed. 2010; 22(4): 200-204.

6. Srirekha A, Kusum B.A comparative analysis of restorative materials used in abfraction lesions in tooth with and without occlusal restoration: Three-dimensional finite element analysis. J Cons Dent. 2013; 16 (2) :157 - 161.

7. VanMeerbeek B, De Munck J, Yoshida Y, Inoue S, Vargas M, Vijay P, et al. Buonocore memorial lecture.Adhesion to enamel and dentin: Current status and future challenges. Oper Dent 2003; 28:215-35.

8. Francisconi LF, Graeff MS, Martins Lde M, Franco EB, Mondelli RF, Francisconi PA, Pereira JC. The effects of occlusal loading on the margins of cervical restorations. J Am Dent Assoc 2009; 140:1275-82.

9. Onal B, Pamir T. The two-year clinical performance of esthetic restorative materials in noncarious cervical lesions. J Am Dent Assoc. 2005; 136:1547-55.

10. Kim JH, Yoon CW, Kim T, Kim HS, Woo DG, Lee KW, Shim JS. Analysis of stress distribution of tooth restored with metal-ceramic crown covering abfraction lesion according to its finish line location under occlusal load. J Korean Acad Prosthodont 2014; 52:305-11

11. Rees JS, Hammadeh M, and Jagger DC, “Abfraction lesion formation in maxillary incisors, canines and premolars: a finite element study," Euro J Oral Scien. 2003; 111(2): 149-154.

12. Srirekha A, Bashetty K. Infinite to finite: An overview of finite element analysis. Indian J Dent Res. 2010; 21:425-32.

13. Eraslan O, Aykent F, Yücel MT, Akman S. The finite element analysis of the effect of ferrule height on stress distribution at post-and-core-restored all-ceramic anterior crowns. Clin Oral Invest (2009) 13:223-227 
14. Tada S, Stegaroiu R, Kitamurs E, Miyakawa O, Kusakari H. Influence of implant design and bone quality on stress / strain distribution in bone around implants: a 3-dimensional finite element analysis. Int $\mathrm{J}$ Oral Maxillofac Implants. 2003; 18:357-368.

15. Sutton AF, McCord JF. Variations in tooth preparations for resin-bonded all-ceramic crowns in general dental practice. Brit D J, 2001; 12: 677-681

16. Fernando Z., Davide A., Roberto S., Valeria F., Raffaella A., Antonio A. Influence of tooth preparation design on the stress distribution in maxillary central incisors restored by means of alumina porcelain veneers: A 3D-finite element analysis. J Dental Mater 2005; 21: 1178-1188.

17. N. Gopi Chander, MDS1 \& T. V. Padmanabhan, MDS2 Finite Element Stress Analysis of Diastema Closure with Ceramic Laminate Veneers. J Prosthod. 2009; 18:577-581.

18. Eraslan O, Aykent F, Yücel MT, Akman S. The finite element analysis of the effect of ferrule height on stress distribution at post-and-core-restored all-ceramic anterior crowns. Clin Oral Invest. 2009; 13:223-227.

19. Li LL, Wang ZY, Bai ZC, Mao Y, Gao B, Xin HT. Threedimensional finite element analysis of weakened roots restored with different cements in combination with titanium alloy posts. Chin Med J 2006;119: 305-11.

20. Toksavul S, Zor M, Toman M, Güngör MA, Nergiz I, Artunç C. Analysis of dentinal stress distribution of maxillary central incisors subjected to various post-andcore applications. Oper Dent. 2006; 31(1): 89-96.

21. Michael JA, Townsend GC, Greenwood LF, Kaidonis JA. Abfraction: separating fact from fiction. Austr Dent J 2009; 54: 2-8

22. Francisconi LF, Graeff MS, Martins Lde M, et al. The effects of occlusal loading on the margins of cervical restorations. J Am Dent Assoc. 2009;140(10):1275-1282.

23. Sorensen JA, Cruz M, Mito WT, Raffeiner O, Meredith HR, Foser HP. A clinical investigation on three-unit fixed partial dentures fabricated with a lithium disilicate glass-ceramic. Pract Periodontics Asthet Dent. 1999;11(1):95-106.
24. Höland W, Schweiger M, Frank M, Rheinberger V. A comparison of the microstructure and properties of the IPS Empress 2 and the IPS Empress glass-ceramics. J Biomed Mater Res. 2000;53(4):297-303.

25. Kheradmandan S, Koutayas SO, Bernhard M, Strub JR. Fracture strength of four different types of anterior 3-unit bridges after thermo-mechanical fatigue in the dualaxis chewing simulator. J Oral Rehabil. 2001;28(4):361-9.

26. Magne P. and Oganesyan T. CT scan-based finite element analysis of premolar cuspal deflection following operative procedures. Int J Perio \& Resto Dent. 2009; 29(4):361-369.

27. Tajima K, Chen KK, Takahashi N, Noda N, Nagamatsu $\mathrm{Y}$, and Kakigawa $\mathrm{H}$ Three-dimensional finite element modeling from CT images of tooth and its validation. Dent Mat J. 2009; 28 (2): 219-226.

28. Pegoretti A, Fambri L, Zappini G, Bianchetti M. Finite element analysis of a glass fibre reinforced composite endodontic post. Biomaterials 2002; 23:2667-2682.

29. Pierrisnard L, Bohin F, Renault P, Barquins M. Corono radicular reconstruction of pulpless teeth: a mechanical study using finite element analysis. J Prosthet Dent 2002; 88:442-448.

30. Gopi NC, Padmanabhan TV. Finite Element Stress Analysis of Diastema Closure with Ceramic Laminate Veneers. J Prostho. 2009; 18: 577-581.

31. Zarone F, Sorrentino R, Apicella D, Valentino B, Ferrari M, Aversa R. Evaluation of the biomechanical behavior of maxillary central incisors restored by means of endocrowns compared to a natural tooth: a 3D static linear finite element analysis. Dent. Mater. 2006; 22:1035-44.

32. Troedson M, Dérand T. Shear stresses in the adhesive layer under porcelain veneers. A finite element method study. Acta Odontol. Scand. 1998; 56:257-262.

33. Sorensen JA, Engelman MJ. Ferrule design and fracture resistance of endodontically treated teeth. J Prosthet Dent 1990; 63:529- 36. 